\title{
Recurrent acute biliary pancreatitis: the protective role of cholecystectomy and endoscopic sphincterotomy
}

\author{
E. J. M. van Geenen - D. L. van der Peet . \\ C. J. J. Mulder · M. A. Cuesta • M. J. Bruno
}

Received: 12 September 2008/ Accepted: 1 January 2009/Published online: 6 March 2009

(C) The Author(s) 2009. This article is published with open access at Springerlink.com

\begin{abstract}
Background Recurrent attacks of acute biliary pancreatitis (RABP) are prevented by (laparoscopic) cholecystectomy. Since the introduction of endoscopic retrograde cholangiopancreaticography (ERCP), several series have described a similar reduction of RABP after endoscopic sphincterotomy (ES). This report discusses the different treatment options for preventing RABP including conservative treatment, cholecystectomy, ES, and combinations of these options as well as their respective timing. Methods A search in PubMed for observational studies and clinical (comparative) trials published in the English language was performed on the subject of recurrent acute biliary pancreatitis and other gallstone complications after an initial attack of acute pancreatitis.

Result Cholecystectomy and ES both are superior to conservative treatment in reducing the incidence of RABP. Cholecystectomy provides additional protection for gallstone-related complications and mortality. Observational studies indicate that cholecystectomy combined with ES is the most effective treatment for reducing the incidence of RABP attacks.
\end{abstract}

E. J. M. van Geenen $(\bowtie)$. C. J. J. Mulder

Department of Gastroenterology, VU-Medical Center Amsterdam, P.O. Box 7057, 1007 MB Amsterdam, Holland

e-mail: ejm.vangeenen@vumc.nl

D. L. van der Peet - M. A. Cuesta

Department of Digestive Surgery, VU-Medical Center

Amsterdam, Amsterdam, Holland

M. J. Bruno

Department of Gastroenterology, Erasmus Medical Center

Rotterdam, Rotterdam, Holland
Conclusion From the literature data it can be concluded that ES is as effective in reducing RABP as cholecystectomy but inferior in reducing mortality and overall morbidity. The combination of ES and cholecystectomy seems superior to either of the treatment methods alone. A prospective randomized clinical trial comparing ES plus cholecystectomy with cholecystectomy alone is needed.

Keywords Acute biliary pancreatitis - Cholecystectomy · Endoscopic sphincterotomy $\cdot$ ERCP $\cdot$ Recurrent

Acute biliary or gallstone pancreatitis (ABP) is an inflammatory condition of the pancreas induced by gallstones [1]. The initial treatment of ABP can be either conservative or interventional. The coexistence of cholangitis is an accepted indication for the performance of endoscopic retrograde cholangiopancreaticography (ERCP). However, whether this procedure is performed for patients with ABP depends on local expertise and guidelines, as is the decision to perform an endoscopic sphincterotomy (ES) [2-5].

After patients have recovered from their first attack of $\mathrm{ABP}$, most guidelines advocate a cholecystectomy to prevent a recurrent attack or other gallstone-related disorders such as symptomatic choledocholithiasis, cholecystitis, gallstone ileus, jaundice, and cholangitis [2-5]. "Recurrent" symptomatic choledocholithiasis after an initial attack of ABP may be preexisting common bile duct (CBD) stones not detected at the time of the primo episode or stones that migrated from the gallbladder into the CBD after initial stone clearance. Choledocholithiasis also may have developed newly within the bile duct after cholecystectomy. 
Table 1 Recurrent acute biliary pancreatitis (ABP)

\begin{tabular}{|c|c|c|c|c|}
\hline Study $^{a}$ & $\begin{array}{l}\text { Recurrent } \\
\operatorname{ABP} \%(n)\end{array}$ & $\begin{array}{l}\text { Recurrent ABP } \\
\text { after ES \% }(n)\end{array}$ & $\begin{array}{l}\text { Recurrent ABP after } \\
\text { cholecystectomy \% }(n)\end{array}$ & $\begin{array}{l}\text { Recurrent } \mathrm{ABP} \text { after } \\
\text { cholecystectomy } \\
\text { and ES \% }(n)\end{array}$ \\
\hline $\begin{array}{l}\text { Kaw, Billi, Hammarstrom, Vazquez- } \\
\text { Lglesias, Gislason }[7,8,22-24]\end{array}$ & & $0.9-6.4$ & & \\
\hline Uomo [6] & $57(7)$ & $5(19)$ & & \\
\hline Kaw [7] & & $2.9(34)$ & $2.4(83)$ & \\
\hline Billi [22] & & $6.4(47)$ & & \\
\hline Hammarstrom [8] & $12.5(16)$ & $2(49)$ & $19(16)$ & $0(15)$ \\
\hline Vazquez-Iglesias [23] & & $2.2(88)$ & & \\
\hline Paloyan [21] & $48(64)$ & & & \\
\hline Kahaleh [79] & & $2.1(96)$ & & $3.0(66)$ \\
\hline
\end{tabular}

ES endoscopic sphincterotomy

${ }^{a}$ All studies are prospective, observational, and nonrandomized

The incidence of recurrent acute biliary pancreatitis varies widely, from $0 \%$ to $57 \%$, depending on the population studied, the initial treatment, and the follow-up time (Table 1). Recently, observational studies point toward a reduction in recurrent $\mathrm{ABP}$ attacks and other gallstone complications when ES is performed for selected groups of patients [6-10]. Based on whether a patient has undergone ES, cholecystectomy, or both, the post-ABP-status of a patient can be classified into four categories: 1 (no ES and no cholecystectomy), 2 (no ES with cholecystectomy), 3 (ES without cholecystectomy), or 4 (ES with cholecystectomy).

To date, no studies have compared any combination of these conditions (Table 1). The current report reviews additional medical interventions to determine which are most effective for preventing recurrent medical problems after an attack of ABP.

\section{Cholecystectomy versus conservative treatment}

Evidence that a cholecystectomy actually reduces the incidence of recurrent ABP is scarce. The evidence that does exist originates mainly from older retrospective studies that observed no recurrent ABP after a cholecystectomy compared with a $25 \%$ to $61 \%$ rate of $\mathrm{ABP}$ recurrence with conservative management [11-17]. From a retrospective population-based cohort study, it was concluded that a cholecystectomy reduces the risk of a recurrent or de novo ABP almost to the same level as found in the general population [18]. The overall age- and sexadjusted incidence of acute pancreatitis before cholecystectomy was 6.3 to 14.8 per 1,000 patient years. Cholecystectomy for patients without a prior ABP attack reduced the relative risk for the development of acute pancreatitis to 2 ( 0.65 per 1,000 person years). The recurrence rate for acute pancreatitis of cholecystectomized patients was 2.7 per 1,000 patient years. However, none of these had a biliary origin. Importantly, $13 \%$ to $14 \%$ of all patients presenting with $\mathrm{ABP}$ have a history of a prior cholecystectomy without having undergone ERCP and ES $[19,20]$.

\section{Endoscopic sphincterotomy versus conservative management}

Uomo et al. [6] prospectively investigated the effect of ES on patients after a first attack of ABP who were considered unfit for surgery. In the ES group, the observed rate of recurrent $\mathrm{ABP}$ was 5\% compared with 57\% in the conservative group after a mean follow-up period of 30 and 23.8 months, respectively. Paloyan et al. [21] confirmed this rate of $\mathrm{ABP}$ recurrence after conservative treatment with their rate of $48 \%$. However, Hammarstrom et al. [8] observed a $12.5 \%$ rate of $\mathrm{ABP}$ recurrence in noncholecystectomized patients during a median follow-up period of 79 months. Other prospective observational studies with various follow-up times showed ABP recurrence rates of $0.9 \%$ to $6.4 \%$ for patients treated with ES alone $[7,8,22$ 24].

Intraoperative choledocholithiasis is present in $13 \%$ to $24 \%$ of patients undergoing cholecystectomy and bile duct exploration for symptomatic gallstone disease [25-29], including $\mathrm{ABP}[29,30]$. In $3 \%$ to $6 \%$ of the patients in whom CBD stones were detected, the stones were asymptomatic without preoperative indicators, negative abdominal ultrasound findings, or laboratory parameters $[25,29,31]$. It is believed that about $15 \%$ of these asymptomatic patients eventually will become symptomatic and require further interventional treatment [32]. 
Table 2 Incidence of common bile duct (CBD) stones in acute biliary pancreatitis (ABP) in relation to time [33-37]

\begin{tabular}{ll}
\hline Time from admission & CBD stones $(\%)$ \\
\hline Admission & $50-70$ \\
$<24$ hours & 45 \\
$<48$ hours & 27 \\
$2-3$ days & 23.1 \\
$4-5$ days & 25 \\
$6-7$ days & 12.5 \\
$>7$ days & 8 \\
\hline
\end{tabular}

Evaluation of the CBD for a planned cholecystectomy to decide on CBD exploration should be scheduled with a tight interval because the prevalence of CBD stones may change in time. In fact, multiple studies have shown that the prevalence of CBD stones in relation to admission time decreases because of spontaneous stone migration [33-37] (Table 2). Conversely, when a CBD is found to be free of stones at admission, this might be not representative for the time of surgery because migration of gallbladder stones into the CBD may have occurred just before the operation.

From a clinical management point of view, patients referred to the surgeon for a laparoscopic cholecystectomy after an attack of ABP can be classified as follows according to what is known about the presence of CBD stones: 1 (cleared CBD after ERCP/ES), 2 (no CBD stones on previous imaging investigations including ultrasound, magnetic resonance cholangiopancreatography [MRCP], endoscopic ultrasound [EUS], and ERCP), or 3 (unknown $\mathrm{CBD}$ stone status). Hence, perioperative $\mathrm{CBD}$ stone clearance is of great importance.

Clayton et al. [38] performed a metaanalysis to compare endoscopic removal of CBD stones and cholecystectomy with cholecystectomy and intraoperative removal of CBD stones in terms of morbidity and mortality. They concluded that both approaches had similar outcomes and that treatment should be determined by local resources and expertise.

Laparoscopic CBD duct exploration seems to be an ideal approach, but most surgeons still are uncomfortable and untrained with this technique. The potential drawback of finding CBD stones intraoperatively is that conversion to an open procedure sacrifices the advantage of the laparoscopic approach. However, a postoperative ERCP may be unsuccessful in clearing the CBD, necessitating a second surgical procedure. Adopting a wait-and-see policy is associated with additional interventions and increased morbidity [32, 39-41]. On the other hand, a "diagnostic" ERCP for detection and potential clearance of CBD stones before surgery is not justified because $76 \%$ to $87 \%$ of patients have no CBD stones, and the costs and potential complications of such an invasive approach are considerable [25-29].

In light of these considerations, preoperative assessment of CBD stones by means of noninvasive and cost-effective procedures such as laboratory values, multi-item scores, and imaging methods is of great clinical relevance. A wide variety of multi-item scores are suggested to be useful, but no two studies have identified the same variables. Factors thought to be discriminative by some are found to be of little use by others [41-63].

Recently, two studies assessed the value of gammaglutamyl-transferase (gGT) as a potential predictor for the presence of CBD stones. Peng et al. [64] investigated patients presenting with cholecystitis and found that there was a $33 \%$ chance of concomitant CBD stones with a gGT higher than $90 \mathrm{U} / \mathrm{l}$ and less than a $2 \%$ chance with a gGT lower than $90 \mathrm{U} / \mathrm{l}$. In 1,002 patients undergoing laparoscopic cholecystectomy for any reason, Yang et al. [65] observed that abnormal gGT values had a sensitivity of $84.1 \%$, a specificity of $72 \%$, a positive predictive value of $22.4 \%$, and a negative predictive value of $97.9 \%$ for detecting concomitant CBD stones before surgery.

Radiologic imaging techniques also can be used to detect CBD stones. Abdominal ultrasound is the safest, cheapest, and least invasive imaging method available for visualizing the biliary tree. Unfortunately, its performance in detecting CBD stones is disappointing, with a reported sensitivity of only $25 \%$ to $58 \%$ and a specificity of $68 \%$ to 91\% [66]. The sensitivity of the CT scan for detecting CBD stones is about $40 \%$, which is too low for it to be of clinical use [67]. However, MRCP is a very accurate method detecting CBD stones, with a reported sensitivity of $82 \%$ to $95 \%$, a specificity of $97.5 \%$ to $100 \%$, a positive predictive value of $95 \%$ to $100 \%$, and a negative predictive value of $90 \%$ to $98 \%$ [33, 68-73].

In a systematic review of seven prospective trails, Ledro-Cano [74] compared the performance between MRCP $(n=411)$ and endoscopic ultrasonography $(n=411)$ in detecting choledocholithiasis. They concluded that both imaging methods had a comparable and very high accuracy in detecting CBD stones. Some individual studies suggest that MRCP has a slightly lower sensitivity for detecting stones than EUS because the sensitivity of MRCP decreases as follows when stones become smaller: $67 \%$ to $100 \%$ for stones larger than $10 \mathrm{~mm}, 89 \%$ to $94 \%$ for stones measuring 6 to $100 \mathrm{~mm}$, and $33 \%$ to $71 \%$ for CBD stones smaller than $6 \mathrm{~mm}$ [69-72]

\section{Endoscopic sphincterotomy and cholecystectomy}

Hammarstrom et al. [8] followed 96 patients after an initial $\mathrm{ABP}$ event in an observational non randomized study for a 
median of 79 months (range, 33-168 months). From this potentially biased study, it was concluded that ES without a cholecystectomy reduced the overall incidence of recurrent pancreatitis event $(4.7 \%$ vs $9.4 \% ; p=0.02)$. Of those patients initially treated using ES, $35 \%$ required an additional cholecystectomy during the follow-up period.

It is reported that $2 \%$ to $33 \%$ of patients with symptomatic choledocholithiasis require an additional cholecystectomy, suggesting that patients with ABP are at greater risk for late gallstone-related complications [7577]. This also is supported by the observation that $15 \%$ of the patients from the Hammarstrom study required an emergency cholecystectomy after ES, compared with only $4 \%$ to $6 \%$ of patients presenting with symptomatic gallstone disease but not ABP [8, 75]. Higher cholecystectomy rates probably are due to the risk of acute cholecystitis after ES, which alone does not have a clear etiology [8, 78].

In a prospective nonrandomized trial, Kahaleh et al. [79] investigated the rate of ABP recurrence after $\mathrm{ES}(n=96)$ compared with ES and cholecystectomy $(n=66)$. The mean follow-up period was 1091 days. The observed rate of ABP recurrence was $2.1 \%$ compared with $3 \%$ ( $p=0.278$ ). Evidently, because of the nonrandomized study design, selection bias cannot be ruled out. Furthermore, this study has been published only in abstract form and other recurrent gallstone complications, for example, are not discussed.

From the literature, the picture emerges that ES reduces the number of recurrent ABP events more than a cholecystectomy. Does this mean that we can skip performing a cholecystectomy after ABP? The answer is not straightforward. McAlister et al. performed a metaanalysis that included five prospective randomized trials [9, 80-83] showing the benefit of an additional cholecystectomy after ES in case of symptomatic gallstone diseases, including ABP [84]. An additional cholecystectomy resulted in a lower death rate $(7.9 \%$ vs $14.1 \% ; p=0.01)$ even in studies that included patients from higher-risk American Society of Anesthesiology (ASA) classes. In the patients for whom a wait-and-see policy was adopted, $16 \%$ experienced the development of biliary type pain or cholecystitis (relative risk [RR], 14.56; confidence interval [CI], 4.95-42.78), and more patients experienced recurrent jaundice or cholangitis (RR, 2.53; CI, 1.09-5.87; $p=0.03$ ), but no significant difference in recurrent ABP rates was observed $(0.3 \%$ vs $1.3 \% ; p=0.39)$. Eventually, for $35 \%$ of the patients subjected to a wait-and-see policy, an additional cholecystectomy was performed, with median follow-up times ranging from 30 to 80 months.

From these data, it seems apparent that a cholecystectomy after an ABP event is beneficial and indicated. What about the timing of the operation? No scientific data exist to guide the timing of surgery. Expert opinion guidelines are based on sound and practical reasoning. Windsor [17] proposed that a cholecystectomy should be performed within 1 month after the first episode of ABP because most recurrent $\mathrm{ABP}$ events occur within 1 month (if no additional ES was performed). When the initial episode of ABP is severe and accompanied by peripancreatic fluid collections or pseudocysts, cholecystectomy should be delayed until the pseudocysts have either resolved or persisted beyond 6 weeks, at which time pseudocyst drainage can safely be combined with cholecystectomy [85].

Hammarstrom et al. [8] investigated the effect of an additional ES after an initial cholecystectomy in preventing recurrent $\mathrm{ABP}$ events. Their data showed a $0 \%$ rate for recurrent $\mathrm{ABP}$ events after cholecystectomy plus ES compared with a $19 \%$ rate for recurrent ABP events after cholecystectomy alone and $2 \%$ after ES alone. These data were not confirmed by Kahaleh et al. [79], who observed no difference between ES and ES plus cholecystectomy in preventing recurrent ABP (2.1\% vs 3.0\%). Furthermore, the high rates of $\mathrm{ABP}$ recurrence after cholecystectomy in the Hammarstrom et al. [8] study were not confirmed by Kaw et al. [7], who reported a rate of $2.4 \%$.

Boerma et al. [80] investigated the outcome of a cholecystectomy for patients whose symptomatic CBD stones, ABP, or both were treated by an ERCP and ES. The patients were randomized into two groups: group 1 (ERCP and ES plus cholecystectomy) and group 2 (ERCP and ES plus a wait-and-see policy). They observed significantly higher rates of conversion from laparoscopic to open procedure in the wait-and-see group than in the cholecystectomy group ( $55 \%$ vs $20 \% ; p=0,01)$. This also was observed by Allen et al. [86] in a prospectively collected database $(25 \%$ vs $4 \% ; p<0.01)$. However, these observations were not confirmed in the metaanalysis by McAlister et al. described earlier.

\section{Conclusion}

Endoscopic sphincterotomy with or without an additional cholecystectomy offers better protection than cholecystectomy alone in terms of reducing the number of recurrent ABP events. An additional cholecystectomy after ES is indicated because studies suggest an added reduction in mortality and morbidity. The proper timing of the cholecystectomy has not been studied and is based on expert opinion. The current consensus is that surgery should be used for mild cases during the same hospital admission and severe cases after 6 weeks. To prevent recurrent ABP events or other gallstone-related disease, CBD stone clearance is an important issue. Therefore, diagnosing CBD stones to establish the proper indication for ERCP with ES and stone removal is an important and clinically 
relevant item. For this, MRCP and EUS are instrumental. Randomized clinical trials comparing the long-term effects of cholecystectomy and ES versus cholecystectomy alone for APB are indicated.

Open Access This article is distributed under the terms of the Creative Commons Attribution Noncommercial License which permits any noncommercial use, distribution, and reproduction in any medium, provided the original author(s) and source are credited.

\section{References}

1. Opie EL (1901) The aetiology of acute haemorrhagic pancreatitis. Bull John Hopkins Hosp 12:182-188

2. Aly EA, Milne R, Johnson CD (2002) Noncompliance with national guidelines in the management of acute pancreatitis in the United kingdom. Dig Surg 19:192-198

3. Bollen TL, Besselink MG, van Santvoort HC, Gooszen HG, van Leeuwen MS (2007) Toward an update of the Atlanta classification on acute pancreatitis: review of new and abandoned terms. Pancreas 35:107-113

4. Kimura Y, Takada T, Kawarada Y, Hirata K, Mayumi T, Yoshida $M$ et al (2006) JPN guidelines for the management of acute pancreatitis: treatment of gallstone-induced acute pancreatitis. J Hepatobiliary Pancreat Surg 13:56-60

5. Banks PA, Freeman ML (2006) Practice guidelines in acute pancreatitis. Am J Gastroenterol 101:2379-2400

6. Uomo G, Manes G, Laccetti M, Cavallera A, Rabitti PG (1997) Endoscopic sphincterotomy and recurrence of acute pancreatitis in gallstone patients considered unfit for surgery. Pancreas 14:28-31

7. Kaw M, Al-Antably Y, Kaw P (2002) Management of gallstone pancreatitis: cholecystectomy or ERCP and endoscopic sphincterotomy. Gastrointest Endosc 56:61-65

8. Hammarstrom LE, Stridbeck H, Ihse I (1998) Effect of endoscopic sphincterotomy and interval cholecystectomy on late outcome after gallstone pancreatitis. Br J Surg 85:333-336

9. Lau JY, Leow CK, Fung TM, Suen BY, Yu LM, Lai PB et al (2006) Cholecystectomy or gallbladder in situ after endoscopic sphincterotomy and bile duct stone removal in Chinese patients. Gastroenterology 130:96-103

10. Macadam RC, Goodall RJ (2004) Long-term symptoms following endoscopic sphincterotomy for common bile duct stones. Surg Endosc 18:363-366

11. Elfstrom $\mathbf{J}$ (1978) The timing of cholecystectomy in patients with gallstone pancreatitis: a retrospective analysis of 89 patients. Acta Chir Scand 144:487-490

12. Semel L, Schrieber D, Fromm D (1983) Gallstone pancreatitis: support for a flexible approach. Arch Surg 118:901-904

13. Ranson JH (1979) The timing of biliary surgery in acute pancreatitis. Ann Surg 189:654-663

14. Frei GJ, Frei VT, Thirlby RC, McClelland RN (1986) Biliary pancreatitis: clinical presentation and surgical management. Am J Surg 151:170-175

15. Kelly TR (1980) Gallstone pancreatitis: the timing of surgery. Surgery 88:345-350

16. Osborne DH, Imrie CW, Carter DC (1981) Biliary surgery in the same admission for gallstone-associated acute pancreatitis. $\mathrm{Br} \mathrm{J}$ Surg 68:758-761

17. Windsor JA (1990) Gallstone pancreatitis: a proposed management strategy. Aust N Z J Surg 60:589-594

18. Moreau JA, Zinsmeister AR, Melton LJIII, DiMagno EP (1988) Gallstone pancreatitis and the effect of cholecystectomy: a population-based cohort study. Mayo Clin Proc 63:466-473
19. Gloor B, Stahel PF, Muller CA, Worni M, Buchler MW, Uhl W (2003) Incidence and management of biliary pancreatitis in cholecystectomized patients: results of a 7-year study. J Gastrointest Surg 7:372-377

20. Sungler P, Holzinger J, Waclawiczek HW, Boekel O, Heinerman PM (2007) Novel concepts in biology and therapy: biliary pancreatitis: urgent ERCP and early elective laparoscopic cholecystectomy. Blackwell Science, Oxford, pp 373-376

21. Paloyan D, Simonowitz D, Skinner DB (1975) The timing of biliary tract operations in patients with pancreatitis associated with gallstones. Surg Gynecol Obstet 141:737-739

22. Billi P, Barakat B, D'Imperio N, Pezzilli R (2003) Relapses of biliary acute pancreatitis in patients with previous attack of biliary pancreatitis and gallbladder in situ. Dig Liver Dis 35:653655

23. Vazquez-Lglesias JL, Gonzalez-Conde B, Lopez-Roses L, Estevez-Prieto E, Alonso-Aquirre P, Lancho A et al (2004) Endoscopic sphincterotomy for prevention of the recurrence of acute biliary pancreatitis in patients with gallbladder in situ: longterm follow-up of 88 patients. Surg Endosc 18:1442-1446

24. Gislason H, Vetrhus M, Horn A, Hoem D, Sondenaa K, Soreide $\mathrm{O}$ et al (2001) Endoscopic sphincterotomy in acute gallstone pancreatitis: a prospective study of the late outcome. Eur J Surg 167:204-208

25. Perry KA, Myers JA, Deziel DJ (2008) Laparoscopic ultrasound as the primary method for bile duct imaging during cholecystectomy. Surg Endosc 22:208-213

26. Riciardi R, Islam S, Canete JJ, Arcand PL, Stoker ME (2003) Effectiveness and long-term results of laparoscopic common bile duct exploration. Surg Endosc 17:19-22

27. Montariol T, Msika S, Charlier A, Rey C, Bataille N, Hay JM et al (1998) Diagnosis of asymptomatic common bile duct stones: preoperative endoscopic ultrasonography versus intraoperative cholangiography: a multicenter, prospective controlled study. French Associations for Surgical Research. Surgery 124:6-13

28. Montariol T, Rey C, Charlier A, Marre P, Khabtani H, Hay JM et al (1995) Preoperative evaluation of the probability of common bile duct stones. French Association for Surgical Research. J Am Coll Surg 180:293-296

29. Shayan H, Kopac D, Sample CB (2007) The role of intraoperative cholangiogram in the management of patients recovering from acute biliary pancreatitis. Surg Endosc 21:1549-1552

30. Bertolin-Bernades R, Sabater-Orti L, Calvete-Chornet J, CampsVilata B, Cassinello-Fernandez N, Oviedo-Bravo M et al (2007) Mild acute biliary pancreatitis vs cholelithiasis: are there differences in the rate of choledocholithiasis? J Gastrointest Surg 11:875-879

31. Gerber A, Apt MK (1982) The case against routine operative cholangiography. Am J Surg 143:734-736

32. Metcalfe MS, Ong T, Bruening MH, Iswariah H, Wemyss-Holden SA, Maddern GJ (2004) Is laparoscopic intraoperative cholangiogram a matter of routine? Am J Surg 187:475-481

33. De WE, Op de BB, De WB, Delvaux G (2007) Magnetic resonance cholangiopancreatography in the preoperative assessment of patients with biliary pancreatitis. Pancreatology 7:347-351

34. Fan ST, Lai EC, Mok FP, Lo CM, Zheng SS, Wong J (1993) Early treatment of acute biliary pancreatitis by endoscopic papillotomy. N Engl J Med 328:228-232

35. Dwerryhouse SJ, Brown E, Vipond MN (1998) Prospective evaluation of magnetic resonance cholangiography to detect common bile duct stones before laparoscopic cholecystectomy. Br J Surg 85:1364-1366

36. Makary MA, Duncan MD, Harmon JW, Freeswick PD, Bender JS, Bohlman $\mathrm{M}$ et al (2005) The role of magnetic resonance cholangiography in the management of patients with gallstone pancreatitis. Ann Surg 241:119-124 
37. Al-Awady HM (1981) The etiological factors in 73 cases of acute pancreatitis. Int Surg 66:145-148

38. Clayton ES, Connor S, Alexakis N, Leandros E (2006) Metaanalysis of endoscopy and surgery versus surgery alone for common bile duct stones with the gallbladder in situ. Br J Surg 93:1185-1191

39. Kondylis PD, Simmons DR, Agarwal SK, Ciardiello KA, Reinhold RB (1997) Abnormal intraoperative cholangiography: treatment options and long-term follow-up. Arch Surg 132:347350

40. Johnson AG, Hosking SW (1987) Appraisal of the management of bile duct stones. Br J Surg 74:555-560

41. Trondsen E, Edwin B, Reiertsen O, Fagertun H, Rosseland AR (1995) Selection criteria for endoscopic retrograde cholangiopancreaticography (ERCP) in patients with gallstone disease. World J Surg 19:852-856

42. Abboud PA, Malet PF, Berlin JA, Staroscik R, Cabana MD, Clarke JR et al (1996) Predictors of common bile duct stones prior to cholecystectomy: a metaanalysis. Gastrointest Endosc 44:450-455

43. Taylor TV, Armstrong CP, Rimmer S, Lucas SB, Jeacock J, Gunn AA (1988) Prediction of choledocholithiasis using a pocket microcomputer. Br J Surg 75:138-140

44. Huguier M, Bornet P, Charpak Y, Houry S, Chastang C (1991) Selective contraindications based on multivariate analysis for operative cholangiography in biliary lithiasis. Surg Gynecol Obstet 172:470-474

45. Hauer-Jensen M, Karesen R, Nygaard K, Solheim K, Amlie EJ, Havig O et al (1993) Prospective randomized study of routine intraoperative cholangiography during open cholecystectomy: long-term follow-up and multivariate analysis of predictors of choledocholithiasis. Surgery 113:318-323

46. Stain SC, Marsri LS, Froes ET, Sharma V, Parekh D (1994) Laparoscopic cholecystectomy: laboratory predictors of choledocholithiasis. Am Surg 60:767-771

47. Barkun AN, Barkun JS, Fried GM, Ghitulescu G, Steinmetz O, Pham C et al (1994) Useful predictors of bile duct stones in patients undergoing laparoscopic cholecystectomy. McGill Gallstone Treatment Group. Ann Surg 220:32-39

48. Houdart R, Perniceni T, Darne B, Salmeron M, Simon JF (1995) Predicting common bile duct lithiasis: determination and prospective validation of a model predicting low risk. Am J Surg 170:38-43

49. Robertson GS, Jagger C, Johnson PR, Rathbone BJ, Wicks AC, Lloyd DM et al (1996) Selection criteria for preoperative endoscopic retrograde cholangiopancreatography in the laparoscopic era. Arch Surg 131:89-94

50. Chan AC, Chung SC, Wyman A, Kwong KH, Ng EK, Lau JY et al (1996) Selective use of preoperative endoscopic retrograde cholangiopancreatography in laparoscopic cholecystectomy. Gastrointest Endosc 43:212-215

51. Alponat A, Kum CK, Rajnakova A, Koh BC, Goh PM (1997) Predictive factors for synchronous common bile duct stones in patients with cholelithiasis. Surg Endosc 11:928-932

52. Golub R, Cantu R Jr, Tan M (1998) The prediction of common bile duct stones using a neural network. J Am Coll Surg 187:584590

53. Onken JE, Brazer SR, Eisen GM, Williams DM, Bouras EP, DeLong ER et al (1996) Predicting the presence of choledocholithiasis in patients with symptomatic cholelithiasis. Am J Gastroenterol 91:762-767

54. Kim KH, Kim W, Lee HI, Sung CK (1997) Prediction of common bile duct stones: its validation in laparoscopic cholecystectomy. Hepatogastroenterology 44:1574-1579

55. Liu TH, Consorti ET, Kawashima A, Tamm EP, Kwong KL, Gill BS et al (2001) Patient evaluation and management with selective use of magnetic resonance cholangiography and endoscopic retrograde cholangiopancreatography before laparoscopic cholecystectomy. Ann Surg 234:33-40

56. Prat F, Meduri B, Ducot B, Chiche R, Salimbeni-Bartolini R, Pelletier G (1999) Prediction of common bile duct stones by noninvasive tests. Ann Surg 229:362-368

57. Roston AD, Jacobson IM (1997) Evaluation of the pattern of liver tests and yield of cholangiography in symptomatic choledocholithiasis: a prospective study. Gastrointest Endosc 45:394-399

58. Kama NA, Atli M, Doganay M, Kologlu M, Reis E, Dolapci M (2001) Practical recommendations for the prediction and management of common bile duct stones in patients with gallstones. Surg Endosc 15:942-945

59. Santucci L, Natalini G, Sarpi L, Fiorucci S, Solinas A, Morelli A (1996) Selective endoscopic retrograde cholangiography and preoperative bile duct stone removal in patients scheduled for laparoscopic cholecystectomy: a prospective study. Am J Gastroenterol 91:1326-1330

60. Menezes N, Marson LP, debeaux AC, Muir IM, Auld CD (2000) Prospective analysis of a scoring system to predict choledocholithiasis. Br J Surg 87:1176-1181

61. Sun XD, Cai XY, Li JD, Cai XJ, Mu YP, Wu JM (2003) Prospective study of scoring system in selective intraoperative cholangiography during laparoscopic cholecystectomy. World J Gastroenterol 9:865-867

62. Sarli L, Costi R, Gobbi S, Iusco D, Sgobba G, Roncoroni L (2003) Scoring system to predict asymptomatic choledocholithiasis before laparoscopic cholecystectomy: a matched case-control study. Surg Endosc 17:1396-1403

63. Grande M, Torquati A, Tucci G, Rulli F, Adorisio O, Farinon AM (2004) Preoperative risk factors for common bile duct stones: defining the patient at high risk in the laparoscopic cholecystectomy era. J Laparoendosc Adv Surg Tech A 14:281-286

64. Peng WK, Sheikh Z, Paterson-Brown S, Nixon SJ (2005) Role of liver function tests in predicting common bile duct stones in acute calculous cholecystitis. Br J Surg 92:1241-1247

65. Yang MH, Chen TH, Wang SE, Tsai YF, Su CH, Wu CW, et al. (2007) Biochemical predictors for absence of common bile duct stones in patients undergoing laparoscopic cholecystectomy. Surg Endose

66. Tse F, Barkun JS, Barkun AN (2004) The elective evaluation of patients with suspected choledocholithiasis undergoing laparoscopic cholecystectomy. Gastrointest Endosc 60:437-448

67. Moon JH, Cho YD, Cha SW, Cheon YK, Ahn HC, Kim YS et al (2005) The detection of bile duct stones in suspected biliary pancreatitis: comparison of MRCP, ERCP, and intraductal US. Am J Gastroenterol 100:1051-1057

68. Romagnuolo J, Bardou M, Rahme E, Joseph L, Reinhold C, Barkun AN (2003) Magnetic resonance cholangiopancreatography: a metaanalysis of test performance in suspected biliary disease. Ann Intern Med 139:547-557

69. Mendler MH, Bouillet P, Sautereau D, Chaumerliac P, Cessot F, Le SA et al (1998) Value of MR cholangiography in the diagnosis of obstructive diseases of the biliary tree: a study of 58 cases. Am J Gastroenterol 93:2482-2490

70. Boraschi P, Neri E, Braccini G, Gigoni R, Caramella D, Perri G et al (1999) Choledocolithiasis: diagnostic accuracy of MR cholangiopancreatography: three-year experience. Magn Reson Imaging 17:1245-1253

71. Zidi SH, Prat F, Le GO, Rondeau Y, Rocher L, Fritsch J et al (1999) Use of magnetic resonance cholangiography in the diagnosis of choledocholithiasis: prospective comparison with a reference imaging method. Gut 44:118-122

72. Sugiyama M, Atomi Y, Hachiya J (1998) Magnetic resonance cholangiography using half-Fourier acquisition for diagnosing choledocholithiasis. Am J Gastroenterol 93:1886-1890 
73. Topal B, Van de MM, Fieuws S, Vanbeckevoort D, Van SW, Aerts $\mathrm{R}$ et al (2003) The value of magnetic resonance cholangiopancreatography in predicting common bile duct stones in patients with gallstone disease. Br J Surg 90:42-47

74. Ledro-Cano D (2007) Suspected choledocholithiasis: endoscopic ultrasound or magnetic resonance cholangio-pancreatography? A systematic review. Eur J Gastroenterol Hepatol 19:1007-1011

75. Riemann JF, Lux G, Forster P, Altendorf A (1983) Long-term results after endoscopic papillotomy. Endoscopy 15(Suppl 1): $165-168$

76. Hammarstrom LE, Holmin T, Stridbeck H (1996) Endoscopic treatment of bile duct calculi in patients with gallbladder in situ: long-term outcome and factors. Scand J Gastroenterol 31:294301

77. Seifert E, Gail K, Weismuller J (1982) Long-term results after endoscopic sphincterotomy. Dtsch Med Wochenschr 107:610614

78. Itah R, Bruck R, Santo M, Skornick Y, Avital S (2007) Gangrenous cholecystitis: a rare complication of ERCP. Endoscopy 39(Suppl 1):E223-E224

79. Kahaleh M, Hall JD, Kohli A, Alaguero CC, Ferre SA, De La Rue SA, et al. (2007) Does cholecystectomy protect from recurrent gallstone pancreatitis after biliary sphincterotomy? A prospective study (abstract). Gastrointest.Endosc. 65:AB223

80. Boerma D, Rauws EA, Keulemans YC, Janssen IM, Bolwerk CJ, Timmer R et al (2002) Wait-and-see policy or laparoscopic cholecystectomy after endoscopic sphincterotomy for bile-duct stones: a randomised trial. Lancet 360:761-765

81. Hammarstrom LE, Holmin T, Stridbeck H, Ihse I (1995) Longterm follow-up of a prospective randomized study of endoscopic versus surgical treatment of bile duct calculi in patients with gallbladder in situ. Br J Surg 82:1516-1521

82. Suc B, Escat J, Cherqui D, Fourtanier G, Hay JM, Fingerhut A et al (1998) Surgery vs endoscopy as primary treatment in symptomatic patients with suspected common bile duct stones: a multicenter randomized trial. French Associations for Surgical Research. Arch Surg 133:702-708

83. Targarona EM, Ayuso RM, Bordas JM, Ros E, Pros I, Martinez J et al (1996) Randomised trial of endoscopic sphincterotomy with gallbladder left in situ versus open surgery for common bileduct calculi in high-risk patients. Lancet 347:926-929

84. McAlister VC, Davenport E, Renouf E (2007) Cholecystectomy deferral in patients with endoscopic sphincterotomy. Cochrane Database Syst Rev (4):CD006233

85. Nealon WH, Bawduniak J, Walser EM (2004) Appropriate timing of cholecystectomy in patients who present with moderate to severe gallstone-associated acute pancreatitis with peripancreatic fluid collections. Ann Surg 239:741-749

86. Allen NL, Leeth RR, Finan KR, Tishler DS, Vickers SM, Wilcox $\mathrm{CM}$ et al (2006) Outcomes of cholecystectomy after endoscopic sphincterotomy for choledocholithiasis. J Gastrointest Surg 10:292-296 